\title{
CENTO E CINQÜENTAANOS DO MANIFESTO DO PARTIDO COMUNISTA: PARA ENTERRAR OS GRANDES MORTOS
}

\author{
Roberval de Jesus Leone dos Santos
}

\section{ORIGENS}

Antes do final do ano de $1847, \mathrm{~F}$. Engels elabora, sem a participação de K, Marx, um catecismo, Principios do comunismo, adotado como esboço do programa da organização que, até meados desse mesmo ano, chamava-se Liga dos Justos e cujos objetivos foram completamente reformulados pelo Congresso que a converteu em Liga dos Comunistas, a partir do abandono da filiação ao socialismo crítico-utópico. ${ }^{l}$ Apesar da forma de elaboração - perguntas e respostas em estilo simples -, feita para convencer e, provavelmente, para evitar que educadores que não soubessem o que queriam perguntassem o que não sabiam e ouvissem o que não queriam, era esparsa e simplificada a concepção de comunismo, haurida da Ideologia alemã, elaborada entre os anos de 1845 e 1846 , e a descrição do sistema capitalista atinha-se mais aos seus resultados (o proletariado, a concorrência, o intercâmbio universal e a dissolução das estruturas arcaicas) do que à gênese a partir da qual se estabelece (a conditio sine qua non do modo de produção, a produção incessante de maisvalia, sequer estava maturada). Apenas para exemplificar, trabalho era ainda confundido com força de trabalho, e a maioria das categorias econômicas, timidamente explicitadas, era, seguramente, fruto da leitura dos extratos de obras de D. Ricardo que possuía. Por outro lado, o postulado da luta de classes e o primado da existência sobre as representaçōes, conseqüentemente a erudição histórica, assim como o credo revolucionário, plenamente desenvolvidos.

Dificilmente a modéstia de $\mathrm{F}$. Engels permitiria dizer que a leitura desse texto dispensa leitura rigorosa do Manifesto do Partido Comunista $(M P C)$, mas a verdade é que este está naquele assentado, pois mesmo

Roberval de Jesus Leone dos Santos. Vinculado à UFBA, é Engcnheiro Civil e estudante do Mestrado em Engenharia no Instituto de Pesquisas Hidráulicas da UFRGS. 
aquelas dez medidas, presentes no $M P C$, que deveriam ser aplicadas após a revolução mundial exigida nos Principios do comunismo (cf. Marx e Engels, 1988, p. 115) e que, contudo, não veio, às quais, já no Prefácio à edição alemã de 1872 , confessam K. Marx e F. Engels, "não se deveriam atribuir nenhuma importância particular" (idem, 1988, p.42), em virtude do acelerado desenvolvimento do capitalismo com relação às ações antitéticas a que elas visavam, são um resumo melhorado das doze medidas existentes nos Principios do comunismo.

A reestruturação dos Principios do comunismo consistiu $\mathrm{cm}$ adiçōes pessoais e no "estilo" emprestado por K. Marx - "estilo", aliás, modificado a partir da Contribuição para a critica da economia politica (1959), uma vez que, já maduro, perdeu o tom sentimental e magoado tão marcante na obra de 1848 , sobretudo no trecho reservado às acusações à burguesia e na excessiva posição de vitima passiva do proletariado, pois aí não estava claramente posto como sujeito da história, e a ruina do capitalismo era compreendida muito mais como tarefa interna do sistema - embora F. Engels deixe bem claro, no Prefácio à edição inglesa de 1888 do $M P C$, com quem aprendeu "a proposição fundamental" (idem, 1988, p.50-51). Por outro lado, algumas passagens contidas na publicação são retomadas em obras posteriores, ${ }^{2}$ o que mostra a sua contaminação com aquele liame que operava o conhecimento construtivista tão próprio dos autores.

$O$ encargo de redigir um manifesto surge notoriamente no II Congresso da Liga dos Comunistas, em 1847, presidida por K. Schapper e secretariada por F. Engels, em Londres, o qual aprova os Estatutos da Liga dos Comunistas, que traziam, na abertura, a mesma convocação constante da última linha do $M P C$, sendo exigência para a filiação e permanência a profissão de fé comunista (cf. idem, 1988, p.122). Na estrutura dos Estatutos da Liga dos Comunistas, é fácil perceber a influência tanto de F. Engels quanto do demônio. ${ }^{3}$ Nessa época, a soberania industrial inglesa era plena entre as naçōes e engendrou o modelo mais acabado de operariado. Embora o coração francês que revoluciona, nas palavras de L. Feuerbach, ainda estivesse limitado ao continente, ${ }^{4}$ a culminação dos presságios se contém nas propostas estabelecidas no $M P C$ e na esteira da indiferença inglesa à crise européia, que é encarada ceticamente por K. Marx como possivel triunfo de um proletariado que só alcançaria, no máximo, a república burguesa e que não possuía ainda o instrumental necessário à sua afirmação (cf. Marx, 1984, p.46-47).

Após uma depuração que demandou tempo, como era próprio do modo de trabalhar dos amigos, c depois de uma notificação formal feita 
pelo Comitê Central da Liga dos Comunistas junto à representação regional de Bruxelas acerca da aplicação de sanção disciplinar ao membro K. Marx, o opúsculo, escrito em alemão, é enviado, em fevereiro de 1848 , a Londres para a publicação. ${ }^{5}$

A rigor, embora K. Marx já tivesse obtido, no exilio francês (18441845) e na pequena viagem á Inglaterra após a expulsão de Paris (janeiro de 1845), conhecimento razoável de economia politica, sobretudo a lei do valor e seu corolário, a lei do salário, de D. Ricardo, as quais são accitas sem correçốes e transpostas para Miséria da filosofia (1847), a fim de refutar Filosofia da miséria (1846), de P. Proudhon, com a dialética hegeliana, já alterada, funcionando de ponta a ponta como fio condutor do dis. curso, o MPC é herança da mesma época, pois somente anos após as intermináveis jornadas na biblioteca do British Museum, no exílio final de Londres (1849-1883), o sistema capitalista estaria compreendido c posto em seus verdadeiros termos em $O$ Capital, ${ }^{6}$ Quer dizer, K. Marx não era ainda, "antes de mais nada, o autor de O Capital" (Aron, 1995, p.133-134).

\section{ESTADO, DIREITO E POLITICA}

Desde a publicação do $M P C$ até hoje, uma das mais acentuadas invectivas da ideologia burguesa é a da rejeição do Estado e a glorificação da política como único locus da práxis. Pois duradoura também é, e vale, em um aspecto cuidadoso, a invectiva de K. Marx e F. Engels: "o poder político do Estado moderno nada mais é do que um comitê ( $A$ usschuss) para administrar os negócios comuns de toda a classe burguesa" (Marx c Engels, 1988, p.68).

Por sua vez, as relações internacionais também evidenciam que o capital é o detentor da prioridade de modificar os elementos coadjuvantes do dominio, isto é, a estrutura do direito. Um exemplo é a relação da es" trutura do direito com a posição atual dos conglomerados transnacionais, pois não necessitando tanto quanto necessitava do direito positivo no interior das nações hoje declina de sua mediação, já que "não é o Estado que impõe sua ordem jurídica sobre esses conglomerados; são eles que, podendo concentrar suas linhas de produção nos paises que oferecerem as melhores contrapartidas para seus investimentos, acabam selecionando as legislações nacionais às quais irão se submeter" (Faria, 1997, p.45).

Se no passado, o importante era ter o Estado como criador da norma realizada à feição dos interesses da classe dominante em dois aspectos: o da aparência, no sentido de exibir um formalismo jurisprudente 
de interesse unitário na sociedade civil, e o da essência, correspondente à chancela das ambições materiais dessa classe, hoje se tem, também, uma simplificação dessa mediação, pois trata-se, numa atitude pragmática, de o próprio capital legislar, com dispensa do Estado, para causas imediatas (no interior do intercâmbio e da produção internacionais e, em menor grau, nacionais) e reservar-lhe a tarefa de cuidar de cláusulas pétreas e da conservação da ordem. Permitir que o Estado atenda a tão amplos e multivariados assuntos normativos seria oneroso pela colossal estrutura que os governos assumiriam e pelo aspecto de interesses internos e externos irreconciliáveis que teria, frustradamente, de satisfazer.

Para as relações interpessoais, a ética é a da mercadoria, já consolidada em cada ser emergente; para a vinculação às amarras da exploração, a ética é a da relação capital/trabalho, sempre havida c imutável em sua gênese; as normas gerais no interior do intercâmbio e da produção ficam, de modo contingente, a critério imediato do capital, e a democracia burguesa, concernente aos atributos elementares da cidadania de classes, permanece com o Estado, pelo menos até que se encontre uma maneira menos formal de também ser arrastada às relações sociais. É por isso que, nos paises de controle, o homem de Estado está em declínio, pois não the cabendo mais o ato de opção entre interesses congruentes, cabe-lhe apenas a sanção de medidas exaustivas, isto é, medidas já consagradas urbi et orbi, cmanadas da ordem internacional e de seu apostolado interno. E, se o Estado nunca pôde ir contra aquilo de que ele mesmo é produto, mais do que nunca no nosso tempo.

A política, embora seja uma atividade ainda necessária para a lógica superestrutural capitalista, é feita por uma multidão de homens perplexos no final das empreitadas, quando as determinações exógenas ao processo caem sobre suas cabeças, ou apáticos perante a convocação para a resolução de problemas donésticos. Como não é possivel esperar, toma a burguesia nacional ela mesma a frente e consolida as suas resoluções, a menos da parcela do lucro devidamente repartida com os políticos corruptiveis, perdendo a política, de longe, para o lugar que ocupara, por exemplo, nas famosas deliberações da Assembléia Nacional do Ano II do calendário revolucionário francês, sob governo jacobino.

Se alguém entende esse processo como o fim da política, ${ }^{8}$ eu diria que é apenas o seu aperfeiçoamento, um aperfeiçoamento positivo para a permanência do sistema. Se a política era feita por homens, trata-se de passar a ser feita também por coisas tangiveis. A convicção aristotélica do animal político estende-se às coisas e às relações sociais, como o capital, no interior da dinâmica capitalista. Houve um deslocamento de agente: 0 
capital não poderia ser portador apenas da essência opressora, era preciso também ter a essência política arrancada ao homem. Se, graças ao Estado, que saneou as condições econômicas mundiais excepcionais posteriores à Segunda Guerra Mundial (1939-1945), houve a retomada, a partir dos Anos Dourados, do processo de trânsito do capital em todo o globo - processo, aliás, iniciado bem antes do Tratado de Versalhes (1919) -, foi, no entanto, o caráter dual do capital, nos últimos anos, que permitiu a ampliação desse processo sob produtividade crescente, incremento da técnica e da informação, concorrência acirrada mas restrita a grandes companhias, escoamento dos volumes de capital volúvel por entre os pólos que o contabilizam e radicalização da divisão do trabalho. ${ }^{9}$

O caráter dual do capital também se manifesta na sua relação com o trabalho: o comando dos acordos provisórios é recuperado pelas representações patronais, enquanto que os sindicatos trabalhistas ficam com a tarefa de empurrar às massas as determinações acordadas nos juizos internos das cmpresas. ${ }^{10}$ É ele que tem os olhos da águia para assegurar o futuro sem as amarras do processo político estritamente humano, e está cada vez mais dificil de admitir que o proletariado, anão, poderia estar sobre os ombros desse gigante cenxergar mais longe, embora o que possa fundamentalmente interessar seja "o que o proletariado $e$ " (Marx c Engels, 1987, p. 38). A chamada feita às esquerdas por V. Lênin, para o combate nos parlamentos mais reacionários e nos sindicatos mais conservadores, é, hoje, apenas uma alegação, em outras palavras, para as barganhas marginais nos acordos prévios às votações.

\section{TRABALHO E ENGAJAMENTO}

O tópico frasal do primeiro capítulo do $M P C$ é quase axiomático: "a história de toda sociedade até hoje é a história de lutas de classes"l (idem, 1988, p.66). Negar a assertiva significa negar o seu enunciado equivalente, o antagonismo de classe, o qual é inseparável do sistema capitalista. Esse antagonismo molda alguns tipos de contradição, que se poderiam chamar persistentes, como a oposição entre interesses do campo e da cidade, a própria relação capital/trabalho, ao lado de outros, emergentes, como a concessão do conhecimento parcial à mão-de-obra ao lado de sua reapropriação incessante pelo capital; o aumento da margem de consumo do proletariado e melhoria de suas condições gerais médias de vida, mais ordinariamente nos países e nas comunidades econômicas controladores, com a diminuição apreciável de sua insurgência e aumento 
do embrutecimento; a oposição entre interesses do capital internacional e doméstico; aumento e diminuição acentuados, respectivamente, das possibilidades de comunicação e da distância entre as nações e declinio das lutas proletárias. ${ }^{12}$

Diferentemente do lupemproletariado, que até hoje em sua maior parte permanece com características gerais semelhantes às de sua origem, como exclusão da atividade produtiva, vedação ao desfrute da maioria dos beneficios governamentais e terreno para a aplicação livre da violência estatal, o proletariado mudou. E mudou porque o sistema que o engendra, para conservar-se, tambèm mudou. Uma das mais significativas mudanças é a do embrutecimento, que, de início, evidenciava-se como conseqüência tanto da ausência de condiçōes sanitárias e salubres de trabalho no proprio processo produtivo quanto da expectativa de vida limitada pela jornada de trabalho e pelo recrutamento de todos os entes familiares; tanto da estrutura ineficiente de produtividade e das tarefas repetitivas próprias de serem executadas por máquinas quanto da falta de qualificação. $O$ embrutecimento é de outro tipo: na medida em que o capital moldou o proletário atual com exigência de qualificação pela revolução na educação, transferência de tarefas grosseiras e repetitivas às máquinas telecomandadas, introdução de sistemas digitais de controle distribuido, diminuição dos espaços de ocupação humana $\mathrm{c}$ aumento do espaço de ocupação dos sistemas informatizados, houve uma internalização do embrutecimento. Criou-se uma "cultura" nova. Continuou-se a negar-lhe a cultura do Aufklärung e impingiu-se-lhe a cultura da fugacidade, que se funda no seguinte: a filosofia bizarra, conservadora e, às vezes, negativa, consistente "na própria linguagem..., no senso comum e no bom senso, na religião popular e, conseqüentemente, em todo o sistema de crenças, superstiçôes, opiniōes, modos de ver e de agir que se manifestam naquilo que se conhece geralmente por "folclore" (Gramsci, 1991, p.21), é retalhada em suas possibilidades de se fracionar e colada aos recursos televisivos, pirotécnicos e computacionais para surgir um elemento desconhecido, mas reconhecido, que escraviza tão-somente os sentidos ${ }^{13}$ e desvia para um local irrecuperável a categoria da reflexão. A estrutura final é um subproduto curioso: quem se permitir visitar os guetos de cultura popular vai desconhecer um elemento que usa a cada momento, pois não há outro subsidio senão o dessa cultura para a manufatura de outra pela instância de controle e por quem ela recruta para difundi-la e mesmo torná-la realizada, já que a cultura erudita, por exemplo, sempre foi proteção da classe dominante e transformada artificialmente $\mathrm{cm}$ algo superior e mistificado: saber da existência de "visa- 
gem", esta ficção que minha mãe garante existir e que, até, jả as viu, foi sempre tão importante para mim quanto ter penetrado a aridez de Guerra e paz, e precisei mesmo de ambas as coisas simultaneamente. O perigo é o que se pode fazer com isso.

A cultura de que trata A. Gramsci, persistente cm alguns guetos e em nossas lembranças, ainda poderia passar pela inversão por ele pretendida, mas não a nova. A maior característica da cultura nova é que frustraria de ponta a ponta a empresa gramsciana de extração dos elementos negativos e inserção do saber constante da filosofia da práxis para a construção da Weltanschauung coerente e unitária. Frustraria, em primeiro lugar, porque não contém estrutura filosófica, ainda que bizarra, pois o filósofo popular está sendo destruido pela era moderna, e aquele salto quantitativo, que a ele deveria ser conferido, está para tornar-se uma piada; em segundo lugar, seria preciso que a própria estrutura, na qual os insumos para o recrutamento promovido pela instância de controle são injetados, fosse apropriada, o que já seria pressuposto de uma sociedade nova, e ai seria paradoxal.

Da passagem do ambiente proposto pela invenção de James Watt, a exemplo dos setores produtivos da Manchester tão bem caracterizada por F. Engels na fase do otimismo juvenil, ${ }^{24}$ até os recintos da Metal Leve ou da Toyota, houve necessidade de revoluções nāo apenas na dinâmica estrutural do cabedal técnico e científico, requeridos hoje - ao contrário de 150 anos atrás - anteriore facto, mas também na metodologia: em menos de um século pelo menos três doutrinas de comportamento no processo produtivo tiveram lugar: o taylorismo, caracterizado pela maximização da produção com minimização do tempo e de execuções com base na psicotécnica e na racionalização dos processos; o fordismo, caracterizado pela incorporação dos avanços do tay lorismo e agregação da produção a custos modestos como fim da própria rotina; e o toyotismo, caracterizado pela economia de escopo e salto qualitativo da produção, formação e autonomia relativa de grupos de trabalho e eliminação das deficiências ainda persistentes nas éticas anteriores. Por outro lado, com o aumento das possibilidades de trafegar mensagens, o ensino dessas éticas não precisou restringir-se mais à jomada de trabalho. Passou a ser ensaiada no próprio ambiente do individuo, chegando através de imagens e sons proliferados por uma rede aparentemente hcterogênea de propostas mas homogênea na resposta final: a fadiga ainda cxistente no interior da produção, ao encontrar o relaxamento no lar, é mais receptiva ao chamamento à doutrina. É por isso que a cultura nova invade e permanece, dissolvendo o passado; a família assalariada, no passado, tinha o 
seu ambiente como uma espécie de célula protetora, na qual, em geral, figurava o compromisso ao contrato e de reproduzir a mão-de-obra, mas quase nenhum outro. Após os acontecimentos decisivos das últimas duas décadas, era preciso o estabelecimento de outros compromissos, dentre os quais a fidelidade ao mundo injusto por parte do proprio trabalhador. $O$ conselho do poeta ${ }^{15}$ pôde ser tomado como imperativo categórico dentro da práxis humana, dentro da convocação feita pclo nosso tempo e aceita por todos nós. A tese humanista do amor á posteridade, admitida pertencente inexoravelmente ao homem, torna-se, pouco a pouco, desprovida de sentido e passa-se a apenas ter-se em vista o carreganento do "fardo familiar", isto é, a odisséia de manter as condições de vida na luta diaria pela sobrevivência sem nenhum vestígio de conteúdo emancipador, mesmo numa campanha paredista. As esperanças, constantes do $M P C$, de que "a burguesia mesma... fornece ao proletariado os elementos de sua própria educação política geral, isto é, armas contra si mesma"'16 (idem, 1988, p.75) é hoje um reconhecimento de que essa mesma burguesia pode recondicionar em seu próprio favor toda a chave do processo, e pode porque, como 0 próprio K. Marx disse na III Tese sobre Feuerbach, "el educador necesita, a su vez, ser educado" (Marx e Engels, 1968, p.666).

Mesmo no setor de serviços, seja com a exigência de qualificação superior ou de qualificação mediana, em que parecem predominar com maior intensidade a necessidade e o espalhamento da informática, é um mito pensar-se que o individuo domina a totalidade do conhecimento formal. Ao contrário, seu dominio insere-se na técnica do fazer, com total desconhecimento dos processos e, talvez, com exceção dos engenheiros de hardware e de software ou dos analistas de sistema, é completa a ignorância acerca do fundamento cientifico e das possibilidades que a tecnologia disponivel pode oferecer. Como é oferecido o menu de altemativas para reproduzir as tarefas, é suficiente compreender a manipulação dos elementos computacionais. Em outras palavras, cm qualquer que seja o local onde esteja a força de trabalho, o conhecimento científico ainda é monopólio do sistema e somente é permitida a sua apreensão por partes, primeiro para que esse mesmo sistema possa extrair as possibilidades da inteligência de un trabalho intelectual no interior dos escritórios, e este, por sua vez, possa incrementar a qualidade dos meios de produção que se fundirão à força de trabalho em outro setor; segundo, como esse conhecimento parcial fica limitado a uma parcela mais qualificada do proletariado, a outra parcela passa a reconhecer-lhe como ente estranho e reciprocamente, sendo ai já uma garantia de segregação interna e criação de conflitos.

Aduzem K. Marx e F. Engels, não obstante: "a burguesia não pode 
existir sem revolucionar continuamente os instrumentos de produção e, por conseguinte, as relações de produção, portanto todo o conjunto das relações sociais" (Marx e Engels, 1988, p.69). Diante disso, pode-se citar uma característica notória dessa era peculiar que é a noção de "mudança" através de certos resultados da revolução incessante que o capitalismo aplica a si mesmo, isto é, através do que chega à superficie: palavras como exagero, por exemplo, perderam quase que totalmente a sua eficácia no sentido de que aos olhos de quem aprecia o espetáculo, isto é, aos nossos olhos, nada mais pode surpreender e tudo que seja hiperbólico tem o dever de sê-lo pouco para o que ainda virá. A sensação de imensidão também perdeu o seu contexto que era o mundo. ${ }^{17}$ Dificilmente hoje, mesmo homens muito cultos, utilizam com a mesma força que tinha, à época de publicação do $M P C$, o sentido de "impossivel". Impossível ainda é, certamente, uma solução de algum problema fundado $\mathrm{cm}$ leis dadas, seja em ciência pura, como, por exemplo, um sistema de equações lineares que não possua ao menos uma solução que as satisfaça simultaneamente, ou em ciência aplicada, por exemplo, a possibilidade de existência de um complexo sistema monolítico de concreto armado nãodimensionado ao esforço de vento em um local de alta velocidade ébli$\mathrm{ca}$, ou filosoficamente falando, impossivel ć tudo o que é efetivamente irrealizável. Perdeu-se o aspecto lúdico das palavias e os termos estão cada vez mais convergindo para o seu "mundo estrito", mundo ao qual poucos pertencem ou têm acesso.

Poder-se-ia indagar, então, por que não há, hojc, tantos homens como E. Kant, que criou todo o seu sistema sem nunca ter saido de sua Kocnigsberg, ao passo que é possível a um pequeno-burguês ou mesmo ao filho de um proletário remunerado por uma holding, isolando-se ainda mais - no caso, em casa -, ter acesso ao mundo inteiro com esforço muito mais modesto do que o acomodado e sistemático filósofo alemão. É que a cultura correspondente a um cidadão de mesma classe social que a de E. Kant não pode ser disseminada pela estrutura atual nem que a instância de controle quisessc. ${ }^{18}$ Além disso, a cultura nova somente pode operar em nós na medida em que estejamos aptos a ignorar $\mathrm{e}$ a conceber apenas, por justaposição, o conhecimento volatil e improvisado, as informações precárias e a retransmissão do saber inútil e verborrágico às gerações que suportarão o peso de nossa omissão e conformismo. Finalmente, como indicou J. P. Sartre, de R. Descartes a K. Marx, as épocas culminadas por homens assim são raras e somente surgem em virtude da existência de relações necessárias na estrutura da sociedade, que os demanda (cf. Sartre, 1978, p.114). 
enterrados, seria preciso já, nem mesmo pressupor, estar-se numa sociedade de outro tipo. Somente com sua realizaçäo plena, após os resultados que trariam esse devenir, o marxismo poderia ser ultrapassado.

\section{REFERÊNCIAS BIBLIOGRÁFICAS}

ARON, R. As etapas do pensamento sociológico. São Paulo: Martins Fontes, $1995,557 \mathrm{p}$.

FARIA, J. E. Direitos humanos c globalização econômica: notas para uma discussão. Estudos Avançados. São Paulo: IEA-USP, v.11, n.30, 1997, p.43-53.

GRAMSCI, A. Concepção dialética da história. Rio de janciro: Civilizaçāo Brasileira, 1991.341p.

MARX, C.; ENGELS, F. La Ideologia Alenana. Montevideo: Pueblos Unidos, 1968. 746p.

MARX, K, As lutas de classes em França. Lisboa: Avantc, 1984, 17\%p.

MARX, K.; ENGELS, F. A sagrada familia. Säo Paulo: Moraes, 1987.207p.

MARX, K.; ENGELS, F. Manifesto do Partido Comunista. Petrópolis: Vozes, 1988. $151 \mathrm{p}$.

SARTRE, J, P. Questão de método. São Paulo: Abril Cultural, 1978, 191p.

\section{NOTAS}

1. Cf. p.95-97 de Marx, K.; Engels, F, Manifesto do Partido Comunista. Petrópolis: Vozes, $1988.151 \mathrm{p}$., onde está conceituado esse tipo de socialismo.

2. A passagem: "toda transformação da ordem social, toda revolução das relaçōes de propriedade, sempre foi a consequiência necessária do nascimento de novas forças produtivas" (idem, 1988, p.112) é retomada, por exemplo, no antológico Prefácio de 1859 : "[...] em certo estágio de desenvolvimento, as forças produtivas materiais da sociedade entram em contradição com as relaçốes de produção existentes [...]. Surge entäo uma época de revolução social" (Marx, K. Contribuiçâa para a crítica da economia politica. Lisboa: Estampa, 1974. 365p., p.29).

3. "O pai [de K. Marx, Einrich Marx], apesar de ter morrido quando Karl acabava de completar vinte anos, parece que via com secreto temor, uma vez ou outra, aquele 'demônio' que tomara conta do scu filho favorito" e "não pensava, nem tão pouco podia suspeitar, que ao transmitir ao filho aqueles caudais de cultura burguesa [...] não fazia mais do que contribuir para dar asas" ao "demônio' que não sabia se seria 'infernal ou celeste" (Mehring, F. Karl Marx. Lisboa: Presença, v. I, 1974, 306p., p.8 c 13).

4. Logo após a publicação do MPC, "a monarquia francesa tinha sido derrubada por uma insurreição, a república proclamada e a revoluçāo européia ti- 
Entretanto, é preciso que não se caia no erro de se imaginar que o conjunto de recursos disponiveis, manipulados pelas instâncias de controle, é um Mal per se. De modo algum: se toda essa estrutura existente, que tem muito ainda a se desenvolver, fosse apropriada por um modo de produção regulado, as potencialidades humanas poderiam alcançar o grau de saturação, enquanto coadjuvante do intercâmbio da verdade. O problema é que pode muito bem o desenvolvimento capitalista chegar a um ponto no qual a destruição da Barbárie na qual se vive - Barbárie, em um certo aspecto, já aventada por T. Adorno e M. Horkheime, cujas admoestações a esse respeito constantes em Dialética do esclarecimento (o último Prefácio é de 1967) parecem, hoje, modestas - não reencontre mais o seu empreendedor, o proletariado enquanto sujeito da história.

Com relação aos intelectuais, cujas tarefas estão escancaradas no antepenúltimo e último capítulos do $M P C$, terminaram por alijar o marxismo às sendas da academia, faltando-lhes até mesmo a atenção para o fato de que a educação do proletariado, hoje um progresso intelectual dificil, pode ser um trabalho para a vida inteira. O marxismo é tomado, onde ele está restrito, como curiosidade acadêmica, pois até mesmo alguns estudantes aprendem marxismo por antonomásia, apesar do esforço e devoção de seus mestres. É pior, no caso, do que ignorar, já que a correção pode ser inviável.

\section{EPÍLOGO}

Por que, todavia, apesar de o mundo ter mudado, de boa parte das passagens do $M P C$ ter conteúdo não desejado inicialmente, conteúdo, digase assim, excessivamente datado, como um de seus autores mesmo o indica; apesar mesmo de não ter concebido que na mesma medida em que poderia o capitalismo vir a colapsar finalmente poderia adiar tanto quanto quisesse esse colapso, a obra, ao completar cento e cinqüenta anos, permanece? É que o espirito fundamental da época não foi destruido, e o capitalismo está condenado a sempre gerar o seu coveiro. A morte do marxismo - de fato, só os grandes disparates ditos por quem acredita no que está dizendo podem tornar-se "verdade" - não é senão uma face desse espírito, porque sempre foi próprio de um sistema dominante empreender a degradação do que critica os seus antagonismos e adiar o alvorecer do novo, principalmente quando se trata de uma empresa que ambiciona o fim mesmo de um regime fundado na exploração, através da revolução do estado de coisas existente. Para que K. Marx c F. Engels fossem efetivamente 
nha sido iniciada" (Hobsbawm, E. J. A era do capital. Rio de Janeiro: Paze Terra, 1988. 343p., p.30).

5. $O M P C$ foi sendo, de modo gradual, publicado aparentemente em muitos idiomas "mas é justo dizer que suas reverberaçőes politicas fora dos pequenos grupos de revolucionários alemães foram insignificantes até que foi republicado no início da década de $1870 "$ (idem, 1988, p.29). No Brasil, a primeira tradução é de Otávio Brandão, publicada em Porto Alcgre no ano de 1924.

6. Nâo é suficiente, com efeito, o conhecimento dos nove volumes de $O$ Capital, pois tanto Contribuição para a crítica da economia politica (1959), por exemplo, onde a questâo do dinheiro é tratada e não mais retomada, quanto as anotações preparatórias e básicas conhecidas como Grundrisse possuem material teórico complementar ao entendimento da história e da natureza do modo capitalista de produção.

7. Escreve K. Marx em A questđo judaica (1844): "[...] o Estado permite que a propriedade privada, a educação $\mathrm{c}$ a profissão actuem à sua maneira, a saber: como propriedade privada, como educação e profissão, e manifestem a sua natureza particular. Longe de abolir estas diferenças efectivas, cle só existe na medida em que as pressupóe" (Marx, K. Manuscritos económicofilosóficos. Lisboa: Edições 70, 1989. 270p., p.44).

8. A prescindência da política, para falar como A. Gramsci, é caráter exclusivo de sociedade regulada.

9. Trata-se de uma maneira de conocber a terceirização cada vez mais crescente, forma de "subcontratação" que "segmenta o mercado garante aos empresários e aos governos maior liberdade na forma de gestão da força de trabalho fora das normalizaçôes e obrigaçôes impostas pelo contrato clou por regulamentos" (Paiva, V.; Potengy, G; Chinelli, F. Qualificação e inserção no mundo do trabalho. Novos Estudos. São Paulo: CEBRAP, n.48, 1997, p.121-142, p.127).

10. Do total de negociaçốes entre sindicatos e empresas no Brasil (cerca de $57,94 \%$ de todas as negociações coletivas), por exemplo, cerca de $61,92 \%$ são feitas diretamente, e o complemento segue para dissidio, sendo que deste cerca de $18,5 \%$ alcança sentenças judiciais (cf. Cardoso, A. M. O sindicalismo corporativo não é mais o mesmo. Novos Estudos. São Paulo: CEBRAP, n. 48, 1997, p. 97-119, p.110).

11. Na edição inglesa de 1888, F. Engels corrige para "A história cscrita" (Marx e Engels, 1988, p.66).

12. Seria possivel, indefinidamente, citar contradiçóes emergentes tanto quanto se quisesse, pois o capitalismo traz inevitavelmente no seu âmago aquela justaposição de lógica racional parcial que, se for conectada no intuito do conjunto e da unidade, destoa em uma năo-razão. Por exemplo, "a abundância de mão-de-obra barata, pouco cscolarizada, qualificada ou organizada continua a ser um atrativo mesmo em tempos globalizados. Pode parecer paradoxal que essas caracteristicas sejam elementos de atraçăo mum momento em que os processos de reestruturação têm a qualidade como elemento ide. ológico básico e se delineia, internacionalmente, um perfil de trabalhador 
caracterizado por alto nivel de escolarização e qualificação [...]. Todavia. nos chamados setores tradicionais da indústria, como o de vestuário, por exemplo, essas características são dispensáveis. O grosso da mão-de-obra realiza tarefas simples, repetitivas, de fácil e rápido treinamento" (Lima, J. C. Negócios da China: a nova industrialização no Nordeste. Novos Estudos. São Paulo: CEBRAP, n.49, 1997, p.141-158, p.143), especialmente em regiōes do globo com aspectos estruturais análogos à do Nordeste brasileiro.

13. E mesmo assim em sua forma deturpada, pois a visão só se satisfaz se não estiver presente a contemplação (é preciso que a dinâmica das exibiçốcs scja pragmática c incessantemente nova) e, presente o som verbalizado em um estilo qualquer, todo o corpo social ć recrutado a participar sob pena de estar indo contra uma moral cstabelecida.

14. Trata-se de Situaçāo da classe trabalhadora na Inglaterra (1845).

15. "Fique torto no seu canto

Não ame" (Drummond de Andrade, C. D. Reuniāo. Rio de Janeiro: José Olympio, 1973.280p., p.41).

16. Já com a alteração introduzida por $F$. Engels na edição inglesa de 1888.

17. Ainda neste ano, um amigo me chamou a atençâo de que un artigo que havia escrito para um simpósio técrico poderia estar, precisamente naquele momento, sendo lido por alguém em qualquer local do mundo. Atentando para o terrivel detalhe, embora me mostrasse cético com relação ao interesse de alguém por aquele artigo, notei que, se fosse um cidadăo europeu do século passado, mesmo estando em Paris, se alguém quisesse ler em Strasburgo o dito artigo antes de entrar para os Anais, eu teria de enviá-lo por via postal e o interessado poderia conhecê-lo somente após "36 horas em 1833" (Hobsbawm, E. J. A era das revoluções. Rio de Janeiro: Paz e Terra, 1989. 366p., p.25).

18. É possivel, no entanto, obter muita informaçấo, até utilizáveis, por meio das redes existentes, especialmente quando se trata de pesquisador no exercicio de sua atividade ou mesmo de individuo que empreenda trocas de informações por intermédio da transferência instantânea de arquivos. Entretanto, é preciso notar que isso não é muito maior do que a reserva de conhecimentos inertes cujo objetivo é precisamente manipular o intelecto, colocada à disposição de quem irá procurá-la sem nenhum planejamento anterior ou capacidade de scleção. E mesmo quem tem essa capacidade de seleção, não por mérito seu mas por imposição das regras increntes ao trabalho de pesquisa (por exemplo, o cumprimento de prazos), não está livre da subordinaçăo necessária às mensagens disponiveis. Qualquer pessoa, hoje, que tenha fácil acesso aos ambientes informatizados pode absorver um arsenal de "curiosidades" de certas personalidades e de acontecimentos recentes na superficie da realidade. Pode saber de cor a configuraçăo política atual do globo ou as letras das canções mais consagradas. Não pode, porém, obter o saber em uma unidade tal que permita penetrar a totalidade e, ainda mais, conceber a trilha pela qual se poderia alcançar a tomada de posição perante o mundo e perante sua própria história. 